\title{
Extended lymph node dissection for gastric cancer from a European perspective
}

\author{
Johan L. Dikken · Marcel Verheij • \\ Annemieke Cats $\cdot$ Edwin P. M. Jansen • \\ Henk H. Hartgrink • Cornelis J. H. van de Velde
}

Received: 27 May 2011 / Accepted: 19 July 2011/Published online: 12 August 2011

(C) The Author(s) 2011. This article is published with open access at Springerlink.com

The extent of lymphadenectomy for the curative treatment of gastric cancer has been subject to considerable debate over the past decades. Despite a plethora of retrospective and single-institution studies comparing different types of lymphadenectomy, only a limited number of randomized controlled trials have focused on this subject. Recently, Tanizawa et al. [1] published an extensive review of existing evidence on lymph node dissection in gastric cancer. This comprehensive review discusses several aspects of lymphadenectomy, including limited versus extended lymphadenectomy, dissection of para-aortal lymph nodes, routine splenectomy and pancreatectomy, and lymph node dissection for early gastric cancer. However, shortly after the review was accepted several relevant and important studies on gastric cancer surgery were published. In the current letter, we wish to give a European perspective on the extent of lymphadenectomy that should

J. L. Dikken · H. H. Hartgrink · C. J. H. van de Velde ( $₫)$

Department of Surgery,

Leiden University Medical Center,

K6-R, P.O. Box 9600, 2300 RC Leiden,

The Netherlands

e-mail: c.j.h.van_de_velde@lumc.nl

J. L. Dikken · M. Verheij · E. P. M. Jansen

Department of Radiotherapy,

The Netherlands Cancer Institute,

Antoni van Leeuwenhoek Hospital,

Amsterdam, The Netherlands

\section{A. Cats}

Department of Gastroenterology and Hepatology,

The Netherlands Cancer Institute,

Antoni van Leeuwenhoek Hospital,

Amsterdam, The Netherlands be recommended for advanced, resectable gastric cancer, and reflect on several more recent developments.

Shortly after finishing accrual of the Dutch Gastric Cancer Group trial comparing D1 with D2 lymphadenectomy, morbidity and mortality results were published, indicating significantly higher mortality after a D2 dissection (10 vs. 4\%) [2], similar to the Medical Research Council Gastric Cancer trial [3]. The number of splenectomies and pancreatectomies, which have shown to increase postoperative mortality, were also higher in the D2 group. Analyses performed after 11 and 15 years of followup revealed no significant differences in overall survival [4, 5]. However, when analyzing cause-specific death at 15 years, gastric cancer-related death was significantly lower after a D2 (37\%) when compared to a D1 (48\%) dissection $(P=0.01)$ [5], suggesting that when postoperative mortality can be avoided, D2 lymphadenectomy improves survival after a gastric cancer resection. A more recent Italian study analyzed D1 versus D2 lymphadenectomy in 267 patients treated in five centers [6]. Although long-term survival results have to be awaited, and the study population might be too small to detect minor differences in overall survival, postoperative mortality after a D2 dissection was only $2.2 \%$. This taken together with the currently performed spleen-preserving gastrectomy indicates that D2 lymph node dissection in experienced centers should be the recommended type of surgery in advanced gastric cancer, also in the Western part of the world.

Avoiding postoperative mortality is a major challenge in gastrectomy, especially when performed in lower volumes like in many European countries. Whereas Japan has established national screening programs for gastric cancer, and has a two- to seven-fold higher incidence rate as compared to European countries, in Europe incidence rates are relatively low, leading to lower exposure of hospitals to 
resectable gastric cancer cases. Although performing randomized studies can significantly improve outcome over a longer period [7], increasing the surgeons' and hospital exposure is the key to improvement in treatment results after low-volume high-risk surgery such as gastrectomy. Many studies have explored the relation between hospital volume and outcome and found that increasing surgeons' and hospital volume is associated with lower postoperative mortality and higher survival rates, both in the Western world and in Asia [8]. In Denmark, this has led to enforced centralization of gastric cancer surgery from 37 to 5 hospitals as of 2003, which has resulted in a significant decrease in postoperative mortality ( $8.2 \%$ in 2003 to $2.4 \%$ in 2008, $P<0.05$ ) and an increase in the number of patients with at least 15 lymph nodes examined (19-67\%) [9]. Centralization of gastric cancer surgery is currently implemented in the UK, Sweden, Finland, and in certain regions in the Netherlands. An additional strategy towards improvement of care is auditing. With auditing, surgeons can improve their results by learning from their own outcome statistics benchmarked against their peers, which is often referred to as the Hawthorne effect. Among other variables of interest, in gastric cancer surgery auditing provides the opportunity to analyze differences in hospital mortality, the extent of lymph node dissection, and the use of laparoscopic techniques. Auditing has proven its value in rectal cancer treatment in Europe [10], and audits for gastric and esophageal cancer are currently present in Denmark, the UK, and the Netherlands.

Meanwhile, the question remains how to treat patients who have undergone suboptimal (D1 or less) surgery for gastric cancer. As the majority of patients in the Intergroup 0116 trial underwent a D0 or D1 dissection, postoperative chemoradiotherapy can be considered to significantly improve survival in these patients [11]. However, in a separate report, the investigators of the Intergroup 0116 trial concluded that D-level designation failed to significantly correlate with survival, although the power to detect such interaction was low [12]. A more recent report, comparing patients treated in the Dutch Gastric Cancer Group trial (who only underwent surgery) with patients treated in several Dutch phase I/II studies with postoperative fluoropyrimidine-based chemoradiotherapy, showed a significant association between postoperative chemoradiotherapy use and improved local control and overall survival after a D1 dissection, but not after a D2 dissection [13]. Also, chemoradiotherapy was highly associated with improved survival after a microscopically irradical (R1) resection. A regimen with capecitabine, cisplatin, and radiotherapy that emerged from the phase I/II studies is currently tested in the international, multicenter phase III CRITICS trial (ChemoRadiotherapy after Induction ChemoTherapy in Cancer of the Stomach). In this trial, perioperative chemotherapy, which proved its value in the MAGIC study [14], is compared with preoperative chemotherapy combined with postoperative chemoradiation [15]. The chemotherapy regimen consists of epirubicin, cisplatin, and capecitabine. For surgery, an extended lymphadenectomy without splenectomy should be performed. Currently participating countries are the Netherlands, Sweden, and Denmark. While a total of 788 patients are needed for this study, accrual as of July 2011 is 367 (47\%).

In conclusion, D2 lymphadenectomy is the recommended type of surgery for advanced, resectable gastric cancer in the Western world. Especially when performed in experienced centers with low postoperative mortality, extended lymphadenectomy brings considerable benefit in terms of gastric cancer-related death. Nationwide initiatives, such as concentration and auditing, can further improve gastric cancer care.

Open Access This article is distributed under the terms of the Creative Commons Attribution Noncommercial License which permits any noncommercial use, distribution, and reproduction in any medium, provided the original author(s) and source are credited.

\section{References}

1. Tanizawa Y, Terashima M. Lymph node dissection in the resection of gastric cancer: review of existing evidence. Gastric Cancer. 2010;13(3):137-48.

2. Bonenkamp JJ, et al. Randomised comparison of morbidity after D1 and D2 dissection for gastric cancer in 996 Dutch patients. Lancet. 1995;345(8952):745-8.

3. Cuschieri A, et al. Postoperative morbidity and mortality after D1 and D2 resections for gastric cancer: preliminary results of the MRC randomised controlled surgical trial. The Surgical Cooperative Group. Lancet. 1996;347(9007):995-9.

4. Hartgrink $\mathrm{HH}$, et al. Extended lymph node dissection for gastric cancer: who may benefit? Final results of the randomized Dutch gastric cancer group trial. J Clin Oncol. 2004; 22(11):2069-77.

5. Songun I, et al. Surgical treatment of gastric cancer: 15-year follow-up results of the randomised nationwide Dutch D1D2 trial. Lancet Oncol. 2010;11(5):439-49.

6. Degiuli M, Sasako M, Ponti A. Morbidity and mortality in the Italian Gastric Cancer Study Group randomized clinical trial of D1 versus D2 resection for gastric cancer. $\mathrm{Br} J$ Surg. 2010;97(5):643-9.

7. Krijnen $\mathrm{P}$, et al. Improved survival after resectable non-cardia gastric cancer in The Netherlands: the importance of surgical training and quality control. Eur J Surg Oncol. 2009;35(7): 715-20.

8. Birkmeyer JD, et al. Hospital volume and surgical mortality in the United States. N Engl J Med. 2002;346(15):1128-37.

9. Jensen LS, et al. Enforcing centralization for gastric cancer in Denmark. Eur J Surg Oncol. 2010;36:S50-4.

10. Birgisson $\mathrm{H}$, et al. Improved survival in cancer of the colon and rectum in Sweden. Eur J Surg Oncol. 2005;31(8):845-53.

11. Macdonald JS, et al. Chemoradiotherapy after surgery compared with surgery alone for adenocarcinoma of the stomach or gastroesophageal junction. N Engl J Med. 2001;345(10): 725-30. 
12. Hundahl SA, et al. Surgical treatment variation in a prospective, randomized trial of chemoradiotherapy in gastric cancer: the effect of undertreatment. Ann Surg Oncol. 2002;9(3): 278-86.

13. Dikken JL, et al. Impact of the extent of surgery and postoperative chemoradiotherapy on recurrence patterns in gastric cancer. J Clin Oncol. 2010;28(14):2430-6.
14. Cunningham D, et al. Perioperative chemotherapy versus surgery alone for resectable gastroesophageal cancer. N Engl J Med. 2006;355(1):11-20.

15. Dikken JL, et al. Neo-adjuvant chemotherapy followed by surgery and chemotherapy or by surgery and chemoradiotherapy for patients with resectable gastric cancer (CRITICS). BMC Cancer. 2011;11(1):329. 